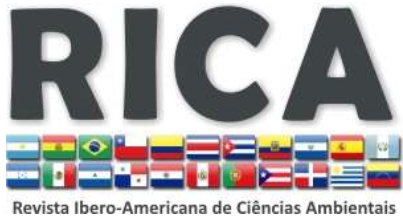

Journals Homepage:

www.sustenere.co/journals

\section{REDUZINDO PERDAS ORIUNDAS DO ARMAZENAMENTO E NO MANUSEIO DE MATERIAIS NA CONSTRUÇÃO CIVIL}

\section{RESUMO}

Nos últimos anos, o crescimento da demanda por moradia e a elevação da concorrência entre empresas que atuam no segmento da construção civil, fizeram com que as organizações desenvolvessem meios de reduzir os custos de produção. Tendo em vista esta necessidade, o presente artigo tem como objetivo apresentar as principais causas da perda de materiais e propor medidas que visem melhorar 0 processo de armazenagem e manuseio de materiais, em uma empresa atuante no ramo da construção civil. Este estudo é de natureza qualitativa sendo utilizado o método explicativo para elucidar as causas e soluções dos problemas que afetam o processo.

PALAVRAS-CHAVES: Desperdício; Controle de Materiais; Obra de Construção Civil; Sustentabilidade Ambiental.

\section{REDUCCIÓN DE LAS PÉRDIDAS DE ALMACENAMIENTO Y MANEJO DE MATERIALES EN LA CONSTRUCCIÓN CIVIL}

\section{ABSTRACT}

In recent years, the growth demand for housing and the rising level of competition between companies operating in the construction industry, made this organizations develop new ways to reduce the production costs. In the view of this need, this article aims to present the main causes of loss of materials and propose new measures to improve the process of storage and materials handling in an active construction company. This study is based on the qualitative method nature and uses the explanatory method to elucidate the causes and solutions to the problems that affect the process.

KEYWORDS: Waste; Materials Control; Civil Works; Environmental Sustainability.
Revista Ibero-Americana de

Ciências Ambientais, Aquidabã, v.6, n.1, Dez 2014, Jan, Fev, Mar, Abr, Mai 2015.

ISSN 2179-6858

\section{SECTION: Articles}

TOPIC: Economia Ambiental

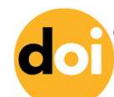

DOI: 10.6008/SPC2179-6858.2015.001.0003

Gilson Alex da Silva

Universidade Paranaense, Brasil http://lattes.cnpq.br/2080953166364830 gilsoncc@hotmail.com

Giovanni Nanni

Universidade Paranaense, Brasil http://lattes.cnpq.br/5132079428684478

gnannibr@gmail.com

Irene Carniatto

Universidade Estadual do Oeste do Paraná, Brasil http://lattes.cnpq.br/7508449720430708

irenecarniatto@gmail.com

Elio Jacob Hennrich Junior

Universidade Estadual do Oeste do Paraná, Brasil http://lattes.cnpq.br/3796212628042916

eliojacob@hotmail.com

Jéssica Ricci de Lima

Universidade Paranaense, Brasil http://lattes.cnpq.br/6452938050442949 jessicaricci1993@hotmail.com

Received: 05/10/2014

Approved: 09/04/2015

Reviewed anonymously in the process of blind peer.

\section{Referencing this:}

SILVA, G. A.; NANNI, G.; CARNIATTO, I.; HENNRICH JUNIOR, E. J.; LIMA, J. R.. Reduzindo perdas oriundas do armazenamento e no manuseio de materiais na construção civil. Revista Ibero-Americana de Ciências Ambientais, Aquidabã, v.6, n.1, p.23-39, 2015. DOI: http://dx.doi.org/10.6008/SPC2179$\underline{6858.2015 .001 .0003}$ 


\section{INTRODUÇÃO}

Nos tempos atuais alguns direitos fundamentais das pessoas têm estado em destaque, tanto na gestão pública, quanto nas mídias sociais. Entre esses direitos muito se tem discutido sobre o direito à moradia digna para cada cidadão. Entretanto, um olhar mais aproximado e cuidadoso tem revelado que estamos longe de atingir essa meta no Brasil, e que inúmeros problemas de origem política, técnica e de gestão da construção estão presentes, dificultando o avanço e o alcance deste objetivo. Assim, é fundamental a análise dos problemas atuais e a implementação de novas propostas para o êxito da construção de moradias com segurança, conforto e em harmonia com o meio ambiente.

Analisando a construção civil em geral, encontramos características como, o pouco uso e o desenvolvimento insuficiente de novas tecnologias; o desperdício de materiais; a baixa qualificação profissional e a baixa qualidade de vida dos trabalhadores. "As fortes oscilações do mercado fazem com que as empresas do setor minimizem seus investimentos, seja em equipamentos, seja em programas de melhoria organizacional e de recursos humanos, incluindose aqui, os programas de qualidade" (SANTOS, 1995, p.32).

Tratando-se do correto uso dos materiais deve-se enfocar que com a ampliação em grande escala do aumento da construção civil, grande tem sido a demanda por exploração de recursos naturais, nesse sentido, sobre o desperdício de materiais, muito se discute sobre a forma correta de recebimento, armazenagem, movimentação e utilização de materiais na construção civil. $\mathrm{Na}$ prática, na maioria das vezes as empresas não seguem um padrão ou norma, geralmente o fazem da maneira que Ihes for mais conveniente. No entanto, estas práticas não se mostram eficazes. Com base em estudos realizados no Brasil até o momento, alguns materiais têm níveis de perda bastante elevados no setor, onerando o custo da obra e consequentemente aumentando a exploração dos recursos naturais. A Construção Civil é vista como uma das principais atividades para o desenvolvimento econômico e social, porém admite-se que ela é também uma grande geradora de impactos ambientais, quer seja pela geração de resíduos, quanto pela modificação da paisagem e pelo consumo de recursos naturais (PINTO, 2005).

Sendo assim, o setor tem um grande desafio pela frente, que será conciliar o aumento da demanda de construções com práticas sustentáveis para diminuição de impactos ambientais gerados por resíduos sólidos (NETO, 2007). Como são de grande e significativa importância para o meio ambiente e para o setor, a razão deste trabalho é a tentativa de analisar a complexidade das causas das perdas de materiais na construção civil onde se questiona: Quais são os pontos críticos do desperdício de materiais? Qual a forma correta de armazenagem e manuseio de materiais dentro do canteiro de obras? Como desenvolver métodos e práticas que visam à diminuição dos índices de perdas de materiais por erros no armazenamento?

Portanto, o objetivo geral deste artigo é aprimorar o processo de armazenagem e manuseio de materiais, visando à diminuição dos custos e dos recursos naturais neste setor e atendendo às normas ambientais vigentes. Os objetivos específicos deste trabalho estão em 
determinar as perdas ocorridas por armazenagem incorreta e no manuseio dos materiais; identificar os pontos críticos que levam a perda dos materiais; propor medidas que visem à redução de desperdício de materiais. Este trabalho objetiva analisar as perdas surgidas durante o processo de recebimento, manuseio e armazenagem apenas dos materiais utilizados na superestrutura, estrutura e alvenaria. Visto que é a fase onde ocorrem os maiores índices de perdas e que vão determinar o sucesso ou não das atividades de revestimento e acabamento, principalmente no que diz respeito ao desperdício de materiais. Ao colocar em prática as medidas visando à redução da perda de materiais, armazenamento, e o controle e distribuição de materiais, permitirá a empresa compreender que, com a adoção das medidas diminuirá as perdas, mostrando assim a efetividade do processo. Visto que, na medida em que se diminuem as perdas de materiais, o custo de produção diminui e eleva-se o percentual de lucratividade.

\section{REVISÃO TEÓRICA}

Nos últimos anos, as empresas de construção civil têm recebido a crítica de pertencerem a um setor desperdiçador de recursos. Segundo Souza et al. (1999), quanto ao uso dos materiais, a geração de entulho é algo sempre noticiado nos meios de comunicação. É de conhecimento de todos que uma boa quantidade de materiais entregue por fornecedores nos canteiros de obras, não são utilizados para os fins os quais foram solicitados. A reciclagem desses materiais é uma opção favorável, pois além de reutilizar, diminui o impacto ao meio ambiente e aumenta a durabilidade de um aterro (CAVALCANTE \& CHERIAF, 1997; BATTISTI et al., 1998; I\&T, 1990, 1995; JOHN, 1999; LEVY, 2002; PINTO, 1989, citado por NETO, 2007). Além do que, sem a destinação correta dos resíduos da construção civil, estes podem contribuir para a poluição do ambiente. Em razão disso, as construtoras normalmente gastam mais materiais em relação à quantidade inicial prevista, o que acaba elevando os custos de produção. No entanto, elas repassam aos clientes aumentando o valor dos imóveis. Contudo, faz-se necessário distinguir perda de desperdício, para podermos compreender melhor esses valores.

\section{Gestão de Materiais}

Administrar recursos materiais segundo Chiavenato (2003) é um dos maiores desafios para gerentes das organizações, pois reúne operações que vão desde a identificação do fornecedor até a entrega do produto. "Um sistema de materiais deve estabelecer uma integração desde a previsão de vendas, passando pelo planejamento de programa-mestre de produção, até a entrega do produto final." (DIAS, 2009, p.3). Esse sistema deve ser capaz de controlar a maior parte dos recursos da empresa, tais como: máquinas, equipamentos, instalações, matéria-prima entre outros. Para que um sistema de gestão de materiais funcione com efetividade, além de organizado deve estar dividido por áreas de concentração. Essa divisão segundo Dias (2009) acontece da seguinte forma: controle de estoques; compras; almoxarifado; planejamento e 
controle da produção; importação; transporte e distribuição. Dessa maneira, cria-se um ciclo em torno da cadeia de suprimentos, onde cada setor realiza operações fundamentais para o desenvolvimento das atividades no canteiro de obras. No entanto o feedback entre os departamentos é crucial para a continuidade do processo.

O controle de estoque é uma ferramenta que se bem utilizada irá gerar vários benefícios para a organização. De acordo com Martins (2003), a gestão de estoques possibilita o administrador verificar se os estoques estão sendo bem utilizados, bem manuseados e bem controlados. Dias (2009), argumenta que a decisão do que estocar, quando e quanto, dependerá da política de estoque da empresa, podendo variar de acordo com o custo de reposição. A administração de materiais através do controle de estoque, juntamente com o acondicionamento de matérias-primas no canteiro de obras estão entre os temas abordados neste trabalho.

\section{Conceito de Perdas}

O conceito de perdas na construção civil é quase sempre associado exclusivamente aos desperdícios de materiais. Deve-se entender, no entanto que, as perdas vão além deste conceito e, portanto, devem ser entendidas como toda ineficiência no que se refere ao uso de equipamentos, materiais e mão de obra. As perdas possuem normalmente uma parcela inevitável e outra economicamente viável de ser combatida. "De fato pode se admitir que exista um nível aceitável de perdas, pois, para reduzi-las além deste nível são necessários investimentos superiores ao valor economizado" (SOIBELMAN, 1993, p.6). As perdas envolvem a ocorrência de desperdícios de materiais, bem como a execução de tarefas desnecessárias e de retrabalho, que geram custos adicionais e que não agregam valor ao produto final. Segundo Formoso et al. (1996) tais perdas são consequência de um processo de baixa qualidade, que elevam os custos e a produção do produto final deficiente.

Para compreender melhor este conceito, é necessário conhecer a natureza das atividades que envolvem o processo produtivo. Tal processo pode ser classificado em atividades de conversão que envolve o processamento de materiais e atividades de fluxo que se relaciona com as tarefas de inspeção, movimento e espera dos materiais. As atividades de conversão são as que normalmente agregam valor ao produto, entretanto quando ocorre a necessidade de retrabalho, realizou-se uma atividade de conversão que não agregou valor. Segundo Koskela (1992 citado por FORMOSO et al. 1996), as novas filosofias de produção sugerem que a ação dos processos pode ser melhorada e as suas perdas diminuídas não só através da melhoria da eficiência das atividades de conversão e de fluxo, mas pela eliminação de algumas dessas atividades. Contudo, deve-se ter cautela para tal prática, pois ao eliminar uma atividade deve-se ter clareza de que a sua falta não trará problemas futuramente. Agopyan et al. (1998) relaciona três estágios onde ocorrem o consumo e perda de materiais no empreendimento: concepção, execução e utilização; A concepção prevê a quantidade de material realmente necessário de acordo com o projeto a ser realizado; Na execução percebe-se a diferença entre a quantidade 
prevista no projeto e a quantidade efetivamente consumida; No estágio de utilização verifica-se a diferença entre a quantidade de material prevista para manutenção e a quantidade consumida em um período.

\section{Estudos Sobre Perdas}

Embora seja de ótima valia para o crescimento da construção civil, muito pouco se tem realizado, em nível de pesquisas, no sentido de obter dados consistentes sobre perdas de materiais no canteiro de obras. As perdas de materiais acontecem principalmente quando entulhos são jogados fora, pois a quantidade de resíduos gerados pelas atividades construtivas nas cidades é tão grande, que se houvesse uma total reutilização do material produzido, a necessidade de pavimentação de novas vias ou construção de habitações de interesse social, por exemplo, poderiam ser supridas (PINTO, 1989 citado por NETO, 2007). Havendo assim a diminuição da exploração e do uso dos recursos naturais. Os estudos existentes no Brasil, não contemplam fases distintas ou setores diferentes do canteiro, além de cada pesquisador utilizar critérios diferentes para calcular os níveis de perda de materiais. Como é possível identificar nos estudos a seguir.

\section{Estudos Realizados por Skoyles}

De acordo com os estudos realizados por Skoyles (1974), as perdas são verificadas através da simples mensuração da diferença entre a quantidade de material entregue na obra e a utilizada para outros fins, incluindo as perdas por mau uso. Segundo o mesmo autor, é impraticável abranger todos os tipos de perdas, devido à grande variedade de materiais e tipos de construção, para ele isso requer um projeto piloto no qual os materiais que forem identificados, produzam perdas mais significativas para que facilite a mensuração.

As dificuldades de se realizar estudos sobre perdas nos canteiros de obra acontecem principalmente quando não há inspeção no recebimento e quando existe a transferência de materiais para outras obras da mesma empresa. De acordo com Skoyles (1974 citado por ROSA, 2001), existe a necessidade de melhorar também a comunicação entre os que projetam e os que constroem, e uma maior atenção deve ser dada ao controle de materiais. Para Skoyles (1974), a principal mudança está relacionada com a atitude de todos os envolvidos no projeto, sejam eles, funcionários da produção, fornecedores, gerenciadores da execução da obra, entre outros que de alguma forma são responsáveis para que ocorram as perdas. Para que tal fato ocorra os envolvidos precisam se comprometer e articular-se entre os setores para alcançar os objetivos propostos. 


\section{Estudos Realizados por Soibelman}

O estudo realizado por Soibelman (1993) objetivou as perdas de materiais nos processos construtivos e principalmente a investigação das suas causas. No estudo, não foram analisadas perdas relativas à utilização de mão de obra. Serviram de objeto de observação oito materiais cujas perdas são consideradas mais relevantes: aço, concreto pré-misturado, cimento, areia, cal, argamassa pré-misturada, tijolos maciços e blocos cerâmicos. O índice de perdas de materiais foi calculado comparando a quantidade teoricamente necessária para a execução dos serviços e a quantidade adquirida no período analisado, verificada através das notas fiscais. Do seu estudo, Soibelman (1993) relata que, a previsão de materiais tende a ser muito imprecisa, podendo comprometer tanto a programação de insumos, quanto a programação financeira. Destaca ainda que, a incidência de perdas depende dos procedimentos específicos de administração de cada material, portando, quando o índice de um produto for elevado não significa que todos os insumos apresentaram perdas elevadas.

Com relação às causas das perdas, é possível destacar que, grande parte delas pode ser atribuída a problemas relacionados ao projeto, principalmente por modificações durante a execução do processo, não cumprimento às especificações e detalhamento insuficiente de projetos, além da falta de coordenação entre os mesmos. Questiona-se no estudo de Soibelman (1993), o papel da mão de obra na geração de perdas, pelo fato de muitos considerarem a maior parte dos operários negligentes ou ainda, os métodos utilizados e fornecidos à mão de obra para mostrar um desempenho eficiente. Onde o próprio autor conclui que as principais causas das perdas são atribuídas ao gerenciamento da produção, fugindo do controle dos operários.

\section{Classificação das Perdas}

Para reduzir as perdas de materiais de construção, faz-se necessário conhecer sua natureza e identificar suas principais causas. Alguns trabalhos realizados anteriormente por Pinto (1989); Soibelman (1993); Picchi (1993) visaram dimensionar a quantificação do desperdício sob as visões físicas ou financeiras, utilizando abrangências distintas apresentando dados que foram muito discutidos. Tendo em vista as controvérsias ainda existentes, em função da dificuldade em se estimar perdas de materiais, num setor tão complexo como o da construção civil, as perdas foram classificadas no presente trabalho, de acordo com sua possibilidade de serem controladas, sua natureza e sua origem. Os critérios de classificação adotados foram ajustados com base nos estudos de Rosa et al. (1998), Skoyles (1974). A organização e planejamento de como e onde os materiais irão ser usados é uma maneira de se evitar desperdício e consequentemente diminuir o uso de recursos naturais (PINTO, 2005). 


\section{As Perdas Segundo seu Controle}

Partindo do pressuposto em que as atividades que não agregam valor possuem perdas elevadas e que, a eficiência das atividades que agregam valor é alta, se eliminarmos uma parcela das atividades que não agregam valor, reduzem-se as demais perdas. Contudo, é possível admitir que exista um nível aceitável de perdas, chamadas inevitáveis que só podem ser reduzido se a empresa passar por uma mudança significativa no patamar de desenvolvimento tecnológico e gerencial. Assim, Soibelman (1993) classifica as perdas da seguinte forma: Perdas inevitáveis ou perda natural: Refere-se a um nível aceitável de perdas cujo investimento necessário para sua redução é maior que a economia gerada, não trazendo retorno financeiro positivo para a organização. Esse nível pode variar de empresa para empresa dependendo do patamar de desenvolvimento da mesma; Perdas evitáveis: Ocorrem quando os custos de ocorrência são maiores que os custos de prevenção. É resultado de um processo de baixa qualidade, onde os recursos são usados inadequadamente. Segundo Formoso et al. (1996), não se pode afirmar que existe um percentual único de perdas para cada material, porém a competitividade da empresa cresce a medida que a organização persegue a redução de perdas continuadamente.

\section{As Perdas Segundo sua Natureza}

A classificação baseada no conceito das sete perdas de Rosa et al. (1998), tem como principal objetivo facilitar a ação gerencial para reduzir as perdas através da identificação das suas origens e natureza. Esta classificação abrange as perdas por: superprodução, substituição, espera, transporte, processamento em si, nos estoques, no movimento, falta de segurança, elaboração de produtos defeituosos, entre outras como vandalismo e roubo. Quanto mais precocemente for identificado o problema, as ações corretivas poderão ser tomadas mais rapidamente, minimizando os impactos e prejuízos à organização.

\section{As Perdas Segundo sua Origem}

As perdas em geral ocorrem e podem ser identificadas durante a etapa de produção. No entanto, sua origem pode estar ligada ainda nos processos que a antecedem, como a fabricação de materiais, projeto, suprimentos e planejamento. Exemplo: Parada na execução dos serviços por falta de material é de natureza de espera e identificado no momento da produção cuja origem está na falha da programação de compras no setor de suprimentos. Outro exemplo de perda que ocorre é nos canteiros de obras, onde há manejo incorreto de resíduos, a identificação e coleta de materiais para reciclagem, diminuiria a compra de mais materiais e baixaria o custo de remoção (PINTO, 2005).Deve haver atenção especial sobre a possibilidade da reutilização de materiais ou mesmo a viabilidade econômica da reciclagem dos resíduos no canteiro, evitando sua remoção e destinação. O correto manejo dos resíduos no interior do canteiro permite a identificação de 
materiais reutilizáveis, que geram economia tanto por dispensarem a compra de novos materiais como por evitar sua identificação como resíduo e gerar custo de remoção.

\section{Indicadores de Perdas}

Os indicadores de perdas de materiais ou sobre consumos podem ser encontrados em diversas fases do processo, pelos quais cada um passa durante a execução do serviço em que são utilizados. Durante o recebimento, quando a quantidade fornecida é menor que a quantidade solicitada, se não corrigido pode ocorrer o consumo inapropriado. O transporte incorreto, por exemplo, pode danificar os materiais a ponto de impossibilitar seu uso normal. Os indicadores globais por obra podem expressar perdas de um material qualquer na obra em geral, como também exclusivamente um serviço executado. "Há de se perceber ainda que, em função de um material ser utilizado em um único ou em vários serviços na obra, pode ser necessária a definição de diferentes tipos de indicadores de perdas: globais por obra, por serviço e por serviço pósestocagem." (SOUZA et al., 1998, p.357). O indicador global por obra é útil para materiais que sejam utilizados em um único serviço, mas pode ser bastante enganoso quando o material é usado em vários serviços na mesma obra.

\section{O Papel dos Índices de Perdas}

Por cumprirem um importante papel no desempenho dos processos produtivos, podem ser utilizados para diferentes finalidades, no entanto, a mais comum é chamar a atenção para o baixo desempenho global do setor em termos de qualidade e produtividade. Apesar disso, não é a principal função dos indicadores de desempenho. De acordo com Formoso et al. (1996), um indicador pode ter a função de dar visibilidade, ou seja, demonstrar o desempenho da organização, indicando seus pontos fortes ou fracos, ou verificando suas disfunções. Dessa forma, é possível avaliar e designar quais são as prioridades para a melhoria da qualidade, bem como os setores onde essas intervenções são mais importantes ou viáveis. Outra função de um indicador é controlar um processo em relação a um padrão pré-estabelecido. Através do monitoramento ao longo do tempo, é possível avaliar o desempenho bem como os desvios e permitir a correção, a tempo, das causas dos mesmos.

Um Indicador pode servir de instrumento para o estabelecimento de metas ao longo do processo de melhoria. Esse tipo de medição visa identificar as oportunidades e verificar o impacto das intervenções no processo de melhorias. Os indicadores ainda cumprem um papel fundamental na motivação das pessoas envolvidas no processo. Sempre que uma melhoria está sendo implantada é importante que um ou mais indicadores de desempenho associados à mesma sejam monitorados e sua evolução amplamente divulgada na organização. Neste sentido, um processo de melhoria visando à redução de perdas de materiais poderia inclusive ser empregado como um instrumento de marketing interno para um programa de qualidade (FORMOSO et al. 
1996, p.6). Para Contador (1997 citado por ROSA, 2001), um produto ou serviço para que não desvie das condições pré-estabelecidas, faz-se necessário estabelecer um padrão de comparação com plano, meta e prazo, visando ao gerenciamento e controle das ações. É muito importante identificar as causas reais dos problemas que resultam em perdas, para que se possa aplicar de forma correta a ação corretiva para cada caso.

\section{METODOLOGIA}

A pesquisa a ser realizada neste trabalho é de natureza aplicada, pois de acordo com Silva (2004) visa gerar conhecimentos para aplicação prática na solução de problemas específicos, de interesse local. Quanto à forma de abordagem faz-se pelo método qualitativo. Justifica-se esta opção, porque conforme Gil (1996) o método não requer utilização de técnicas estatísticas, sendo o ambiente natural a fonte direta para coleta de dados. Classifica-se a pesquisa a ser realizada quanto ao objetivo como explicativa, porque segundo Gil (1996) visa identificar os fatores que contribuem para a ocorrência dos fenômenos ou das variáveis que afetam o processo. Para tanto, de acordo com Lakatos (2001), utilizou-se do procedimento da observação direta, registrando in loco as atividades pesquisadas.

Quanto aos procedimentos técnicos, este trabalho está embasado pela pesquisa bibliográfica em materiais como, artigos publicados, livros, revistas e sites relacionados com o tema, que darão suporte para a elaboração do texto a partir dessas leituras. Os dados coletados serão analisados com o objetivo de encontrar causas referentes à perda e o desperdício, além de sugerir medidas de minimização das perdas de materiais utilizados na construção de casas populares no distrito de São Lourenço, município de Cianorte.Sendo norteadoras desta pesquisa as seguintes questões: Qual a importância do estudo das perdas e sua colaboração para o desenvolvimento do setor? Quais seriam as principais causas da perda de materiais neste caso? O que poderia ser feito para minimizar o desperdício e o uso de recursos naturais e aumentar a eficiência e a eficácia dos aspectos estudados?

\section{RESULTADOS}

O combate ao desperdício, existente por erros de armazenamento em obras, deve-se começar pelo seu entendimento e sua quantificação. Este trabalho objetivou a análise dos dados coletados em uma obra em São Lourenço-PR, enfatizando as perdas ocorridas e os pontos críticos, bem como a sugestão de medidas para a redução das perdas por armazenamento incorreto de materiais. A empresa acreditava no início da obra que, os próprios empreiteiros administrariam os materiais e os manuseariam de forma correta, sem que houvesse a necessidade de um encarregado. Nesta fase, toda e qualquer pessoa tinha acesso ao estoque sem que houvesse controle algum. Por falha de gerenciamento, não havia uma pessoa treinada e habilitada para receber os materiais e acondicioná-los em local adequado. 
O envolvimento dos operários ou do pessoal do administrativo que dão suporte ao trabalho de canteiro é fundamental para o sucesso de qualquer iniciativa de melhoria, quer seja de elaboração de projetos, no suprimento de materiais, máquinas e equipamentos, indo até ao próprio recrutamento, seleção, contratação e administração da mão de obra (LIMA, 1993, p.52). Materiais como cimento e cal, eram armazenados no chão a céu aberto, cobertos por uma lona plástica, não havendo um local adequado para alocá-los. A cal virgem por não se solidificar, mesmo estando em local impróprio, foi aproveitada em sua totalidade, havendo perda apenas por derramamento de material devido a furos na sacaria. "A falta de acuracidade de estoque gera uma série de efeitos indesejáveis para os processos internos e externos das organizações." (DROHOMERETSKI, 2010, p.145). Após três meses de obra, foi realizada uma coleta em todos os 15 barracos espalhados pela obra que armazenavam materiais, onde se constatou a perda de 232 sacos de cimento tornando-se impossível sua utilização pelo fato de estar empedrado.

Segundo Formoso et al. (1996), podem resultar tanto em perdas de materiais quanto de capital, a deterioração do cimento devido ao armazenamento em contato com o solo e/ou em pilhas muito altas. A ilustração seguinte menciona a forma correta de armazenamento da cal, cimento, argamassa e gesso (Figura 1). Nos recebimentos de blocos cerâmicos foi observado que não se encontravam protegido de chuvas e não estavam paletizados. Também não havia critérios no empilhamento, sem altura máxima definida, tendo como consequência o tombamento das pilhas e quebra dos blocos. Em duas amostragens realizadas na obra, tendo como base a quantidade recebida e a quantidade utilizada, as perdas de blocos cerâmicos foram de $15 \%$ e $17 \%$ respectivamente.

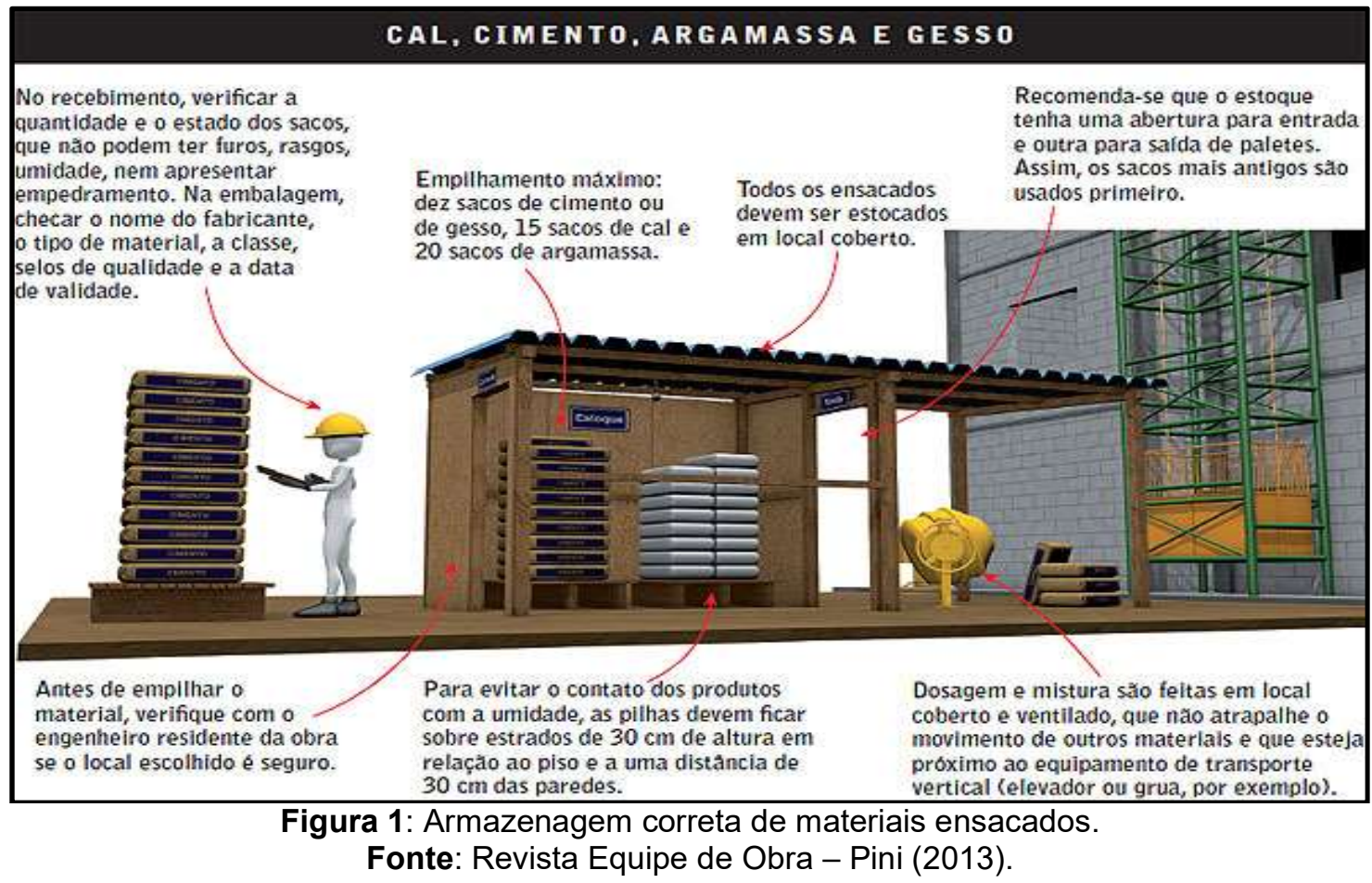

No caso do armazenamento de madeira foi ainda mais grave. Os sarrafos utilizados para fazer gabaritos, as tábuas para confecção de caixarias e as vigas $5 \times 10 \mathrm{~cm}$, estavam espalhadas por toda a obra. Por não estarem empilhadas e protegidas, estas empenaram e foram refugadas 
não servindo mais para o fim a qual foram requisitadas. Uma parte foi posteriormente reaproveitada para a confecção de andaimes, reduzindo o percentual de perdas de madeira serrada que até aquele momento era de $22 \%$ em relação à quantidade adquirida, conforme a tabela seguinte.

Quadro 01: Perda por armazenamento incorreto de materiais na obra de São Lourenço.

\begin{tabular}{|l|l|l|l|l|}
\hline Materiais & Quantidade Adquirida ${ }^{1}$ & $\begin{array}{l}\text { Perda identificada } \\
\text { (un) }\end{array}$ & $\begin{array}{l}\% \text { de perda em relação ao total } \\
\text { adquirido }\end{array}$ & Perda em $\mathrm{R}^{{ }^{2}}$ \\
\hline Bloco cerâmico & 363.600 (peças) & 58.176 (peças) & $16 \%^{3}$ & $29.088,00$ \\
\hline Cimento & $1.500($ sacas) & $232($ sacas) & $15,5 \%$ & $4.756,00$ \\
\hline $\begin{array}{l}\text { Madeira } \\
\text { serrada }\end{array}$ & $42,72\left(\mathrm{~m}^{3}\right)$ & $22 \%$ & $5.170,00$ \\
\hline
\end{tabular}

${ }^{*}$ 1 Valores adquiridos até o terceiro mês de obra. ${ }^{2}$ Baseado na média de preço pago no período. ${ }^{3}$ Valor com base na média das amostragens realizadas.

No período inicial da obra, ocorreram divergências no estoque e foi constatado através de verificação in loco, que houve perdas por roubo externo e roubo interno. Tal fato pode ser atribuído aos próprios funcionários e a terceiros, que entraram na obra devido à falta de vigilância por parte da empresa. Não foram possíveis mensurações da quantidade nem do valor perdido devido ao fato de não haver controle do estoque, nem tampouco outros meios que comprovassem tal fato ocorrido, devido à empresa não possuir nenhum tipo de fiscalização até aquele momento.A falta de um diagnóstico do estoque gera uma série de efeitos indesejáveis para os processos internos e externos das organizações. "A falta de acuracidade de estoque é um problema grave para as organizações, no entanto o impacto dependerá do contexto envolvido" (WALLER et al. 2006, citado por DROHOMERETSKI, 2010, p.145). Estes fatos escondem normalmente altos custos que podem chegar a cifras de bilhões, dependendo do segmento e porte da organização.

Após o levantamento das perdas e análises dos resultados, constatou-se que os pontos críticos encontravam-se nos seguintes procedimentos: pedido de compra sem verificação do estoque existente no canteiro; erros de comunicação em relação às quantidades e tipo do produto a ser comprado; recebimento sem critérios de qualidade e medição definidos; falta de controle na entrega dos materiais para sua utilização. De acordo com Chiavenato (2003) a tarefa da administração é a de interpretar os objetivos propostos pela organização, transformando-os em ação organizacional por meio de planejamento, organização, direção e controle de todos os esforços realizados em todos os níveis da empresa, para que os envolvidos não percam o foco principal. Tendo em vista a gravidade da situação e o tamanho do empreendimento, a diretoria, engenheiro e encarregados da obra, discutiram sobre as práticas envolvidas no processo, e em comum acordo elaboraram algumas medidas para reduzir a perda de materiais, sendo definidas também as responsabilidades de cada um dos envolvidos no processo.

\section{Medidas para Reduzir o Desperdício de Materiais}

As medidas adotadas pela empresa que estão relacionadas à mão de obra foram: aperfeiçoamento técnico, treinamento e fiscalização constante. Para os aspectos especificamente 
relacionados com o desperdício de materiais, as medidas foram: organização do canteiro e reaproveitamento de alguns materiais, alteração de layout e construção de ambientes para melhor acondicionamento de materiais. Para que o material continue em boas condições até chegar ao local onde será aplicado, recomenda-se o treinamento dos colaboradores com base no método de manuseio constado no procedimento de cada um deles; seja através de carrinho de mão, empilhadeira ou manual. Vale lembrar que ao chegar ao local de utilização deve-se manter o material armazenado nas mesmas condições que se encontrava antes do transporte.

\section{Organização e Segurança do Almoxarifado}

Com o crescimento do setor da construção e da quantidade de empreendimentos em execução no país, os furtos e roubos nos canteiros promovem um grande desafio aos construtores de acordo com Medeiros (2013). Em especial, através de observação, no canteiro da obra de São Lourenço, foi possível detectar a ausência de ferramentas, cimento, esquadrias, ferragens, fios e cabos elétricos. Para tanto, foram tomadas algumas medidas visando à inibição destes acontecimentos. Segundo Medeiros (2013), as recomendações mais importantes para evitar perdas por furtos e armazenamento incorreto, consiste em redobrar os cuidados com os almoxarifados, posicionando-os em local seguro; contratar um almoxarife e um vigia noturno no canteiro; construir muro ou cercar o empreendimento antes do início da obra, facilitando o controle de entrada e saída de pessoas a fim de evitar o acesso de pessoas não autorizadas. Para melhor organização dos materiais adquiridos e a redução das perdas por armazenamento, na obra de São Lourenço foram construídos seis ambientes seguros e separados entre si para melhor organização dos materiais. Para as barras de canos construíram-se estaleiros cobertos e divididos por tipo de cano e diâmetro. Os materiais elétricos e conexões hidráulicas, assim como as louças e metais tiveram maior segurança devido ao valor dos mesmos.

\section{Estabelecer Procedimento de Compra e Ressuprimento}

A forma de ressuprimento adotado pela construtora segundo Ribeiro (2006) é o modelo de estoque para demanda, onde os lotes de reposição são determinados de acordo com a produtividade e a etapa em que a obra se encontra. A partir do cronograma físico de atividades gerado pelo planejamento da produção, determina-se a quantidade necessária e se o mesmo encontra-se na obra. A necessidade de materiais é verificada pelo engenheiro da obra, primeiramente através do planejamento de materiais elaborado a partir do cronograma básico da obra. Segundo Ribeiro (2006), para a realização da requisição do material deve-se levar em consideração além do planejamento inicial, o avanço da obra e os levantamentos mensais realizados pelo almoxarife do estoque existente.

Após o levantamento do material a ser adquirido, o engenheiro da obra envia o pedido para o setor de suprimentos por meio de uma ordem de compra. O setor de compras faz a 
cotação dos materiais nos fornecedores cadastrados, identificando qual deles possui a melhor proposta. Os materiais que passaram por solicitação de compra durante a obra foram o cimento, areia, pedra brita, blocos cerâmicos, material elétrico, esquadrias, madeira serrada e chapas de madeirite. Os materiais controlados devem conter procedimentos, estabelecendo as especificações para compra, pois cada serviço tem sua particularidade para execução e exige materiais com características específicas. Devido a isso, deve-se informar na requisição toda informação necessária para que seja comprado o produto adequado. "Nesses casos o trabalho de especificação consiste em adquirir a norma pertinente, treinar o pessoal envolvido em seu uso e colocá-la em prática." (SOUZA \& ABIKO, 1997, p.19).

No caso do cimento, por exemplo, especificar NBR (Norma Brasileira) para todos os materiais, o tipo e classe do material. No caso da areia, deve-se especificar sua granulometria (fina, média ou grossa). Esse processo deve ser feito em qualquer material que seja caracterizado crítico e esteja relacionado no PQO (Plano de Qualidade da Obra).

\section{Conferência e Inspeção no Recebimento de Materiais}

Ao ser entregue na obra, os materiais devem ser inspecionados pela pessoa responsável, geralmente o almoxarife, que deve ter treinamento para executar essa etapa. Além das verificações que são comumente feitas em qualquer estabelecimento, como valor e prazo de pagamento, deverá verificar também o material com a nota fiscal de recebimento e conferir se todas as especificações emitidas na requisição estão sendo atendidas. Durante o recebimento, os fornecedores passam por uma avaliação com critérios relacionados à pontualidade na entrega, qualidade e quantidade do produto recebida. O material adquirido e entregue na obra passa pelo controle de recebimento, do qual resultam os registros de qualidade. Tais registros e avaliação da obra, em relação ao prazo da entrega e ao desempenho do material durante a sua aplicação, prestam-se à retroalimentação do sistema (SOUZA \& ABIKO, 1997, p.17).

Logo após a implantação do plano de redução/perdas de materiais, foram feitas verificações de duas cargas de blocos cerâmicos, onde foi constatado através da cubicagem do caminhão, que a quantidade recebida apresentava déficit de $2 \%$ ou 225 unidades a cada lote em relação à solicitada no pedido de compra. Segundo Souza et al. (1995), a elaboração de especificações, discriminando as características e os limites de tolerância que os materiais devem cumprir, é condição necessária, porém não suficiente para garantir a qualidade na aquisição.

\section{Controle de Materiais}

Todos os materiais controlados devem conter em seu procedimento especificações sobre sua armazenagem ou se referir a medidas adotadas pelo fabricante. "Quando compram, os clientes adquirem mais do que um mero produto, eles também adquirem o pacote de serviços que acompanha o produto" (ALMEIDA JUNIOR, 2000, p.32). Os materiais devem também estar 
separados por lotes e utilizar-se o sistema PEPS (primeiro que entra, primeiro que sai), ou seja, os lotes mais antigos devem estar em locais de fácil acesso para que sejam esgotados primeiramente. Esta prática evita que a maior parte dos materiais tenha o prazo de validade ultrapassado pela data recomendada pelo fabricante.

"A imprecisão dos registros de estoque resulta, na maioria das vezes, em um sistema de registros ineficiente e da baixa qualificação da mão-de-obra" (ARNOLD, 1999 citado por DROHOMERETSKI, 2010, p.149). O mesmo autor aponta alguns fatores que causam os erros nos registros de estoque, sendo eles: falta de segurança no armazém; falta de regularidade na realização dos inventários: falta de treinamento; retirada de material sem autorização; sistema de registros de estoque com inconsistência.

\section{Identificação dos Produtos nos Estoques}

Após ser inspecionado, todo material controlado deve ser identificado, com alguma placa ou etiqueta, de acordo com o local em que se encontra para a melhor visibilidade. Além de identificar o nome do material, nesta ficha pode conter ainda observações com especificação e local de uso. Segundo Almeida Junior (2000), para que a identificação dos materiais facilite o rastreamento futuro, é preciso adotar e definir critérios, desde a entrada de matérias-primas até a entrega das obras acabadas. A identificação dos materiais comprovará que o mesmo foi inspecionado. Nesta operação deve-se incluir o nome do responsável pela verificação e se o material em questão está liberado para uso ou não. A identificação ainda auxilia no bom funcionamento do sistema PEPS (Primeiro que entra, primeiro que sai), pois nela terá a data de recebimento do material e sua validade. Faz-se importante ter um mesmo modelo de identificação, inclusive para material não liberado, ou reprovado. Essa identificação deve estar bem visível para todos, com letras ou borda vermelhas para chamar a atenção, com o intuito de que o material não seja utilizado de forma alguma por nenhum colaborador, pois pode vir a causar um problema futuro mais grave.

\section{CONCLUSÕES}

Este estudo foi desenvolvido buscando reunir as diversas teorias já existentes e consolidadas na literatura, como base para analisar os motivos das perdas ocorrentes durante a armazenagem de materiais. Assim, foi possível através da pesquisa in loco compreender melhor a importância de alocar os diversos materiais de forma correta no canteiro de obras. Contudo, existe a necessidade de uma gestão e controle operacional interno eficiente, para que a distribuição de materiais e a execução do projeto não sejam prejudicadas devido à má localização e condições de não conformidade da matéria prima. Este trabalho objetivou, na primeira fase, verificar as perdas por armazenagem explicitando os materiais que tiveram perdas mais significativas, bem como 
identificar as principais causas que levam a perda de materiais, com o intuito de elaborar medidas para agir no foco do problema. Na segunda fase, esta pesquisa teve como objetivo propor medidas que auxiliem na redução do desperdício de materiais durante o armazenamento e na reposição dos mesmos, enfocando a redução do custo de materiais perdidos e a melhor conservação das matérias primas, buscando a diminuição dos recursos naturais necessários.

Quanto ao objetivo da pesquisa, que foi o de sugerir métodos para o processo de armazenagem e manuseio de materiais, visando à diminuição dos custos, podendo-se concluir que tais resultados foram alcançados. Essa afirmação justifica-se pelo fato da empresa ter padronizado o processo de compra e o recebimento de materiais com as devidas exigências, e por ter iniciado a gestão e o controle dos estoques com métodos de fácil aplicação. Essas medidas resultaram na maior praticidade, principalmente no setor de compras, contribuindo também para o resultado financeiro positivo da empresa, gerando a satisfação dos proprietários. Alguns autores relatam que para obter sucesso no processo como um todo, além de gerir e controlar os materiais, o responsável pelo recebimento deve observar as condições do produto no momento de recebê-lo, uma vez que aceito, o material não conforme se torna prejuízo para a organização. Neste sentido, verificou-se que é necessário, além do planejamento do layout e da estrutura do canteiro, o treinamento adequado do pessoal envolvido em cada um dos setores, melhorando o desempenho de suas funções, maximizando os ganhos para a empresa e buscando a sustentabilidade ambiental na gestão da construção civil.

Este trabalho contribuiu para o melhor entendimento dos conceitos, realizando-os na prática do dia a dia do canteiro. A falta de pessoal tecnicamente habilitado para trabalhar no controle e gestão dos materiais foi um fator que limitou o processo de melhorias. Contudo, a maior precisão das informações relativas ao estoque e a melhora na comunicação entre almoxarifado e setor de compras, contribuíram para que a empresa reconhecesse melhoras significativas dos custos e maior eficácia do processo de abastecimento da obra. O presente artigo buscou também enfatizar o crescente aumento do uso de recursos naturais devido à alta demanda por construções, que consequentemente geram impactos ao ecossistema. Uma das maneiras propostas para baixar estes níveis de poluição na zona urbana é a reutilização de resíduos deixados em canteiros ou de materiais que não serão mais utilizados na obra que podem servir para pavimentação ou fabricação de argamassa, por exemplo.

No Brasil, estudos e iniciativas desta natureza são cada vez mais buscados pelas organizações, por se tratar de práticas que têm um custo benefício compensador. Faz-se então necessária a ampliação desta gama de estudos, para que práticas como esta se concretizem na realidade do setor e proporcionem à sociedade, através da concorrência, melhor qualidade e preços mais acessíveis no mercado imobiliário e maior eficiência no uso dos recursos naturais. Para trabalhos futuros, sugerimos aprofundar os estudos no reaproveitamento e reciclagem de materiais, e a sustentabilidade e responsabilidade social da construção civil.

\section{REFERÊNCIAS}


AGOPYAN, V.. Alternativas para a redução do desperdício de materiais nos canteiros de obras. São Paulo: Universidade de São Paulo, 1998.

ALMEIDA JUNIOR, L. A.. O gerenciamento do suprimento, manuseio e armazenamento na construção civil. Monografia (Mestrado) Universidade de Taubaté, Taubaté, 2000.

CHIAVENATO, I.. Introdução à teoria geral da Administração: uma visão da moderna administração das organizações. 7 ed. Rio de Janeiro: Elsevier, 2003.

DIAS, M. A. P.. Administração de materiais: princípios, conceitos e gestão. 6 ed. São Paulo: Atlas, 2009.

DROHOMERETSKI, E.; FAVARETTO, F.. Um levantamento das causas e efeitos da falta de acuracidade nos estoques: um estudo exploratório. Revista Gestão Industrial, Paraná, v.6, n.2, p.142158, 2010.

FORMOSO, C. T.. As perdas na construção civil: conceitos, classificações e seu papel na melhoria do setor. Porto Alegre: Universidade Federal do Rio Grande do Sul, 1996.

GIL, A. C.. Como elaborar projetos de pesquisa. 3 ed. São Paulo: Atlas, 1996.

LAKATOS, E. M.; MARCONI, M. A.. Fundamentos da metodologia científica. 4 ed. São Paulo: Atlas, 2001.

LIMA, I.. A adequação das pioneiras teorias administrativas ao gerenciamento dos canteiros de obras. São Paulo: ENEGEP, 1993.

MARTINS, P. G.. Administração de materiais e recursos patrimoniais. São Paulo: Saraiva, 2003.

MEDEIROS, H.. Roubo no canteiro. 37 ed. São Paulo: Equipe de obra, 2011.

NETO, A. G. C.. Construção civil sustentável: avaliação da aplicação do modelo de Gerenciamento de Resíduos da Construção Civil do SINDUSCON (MG) em um canteiro de obras - um estudo de caso. Dissertação (Mestrado em Programa de Pós-Graduação em Saneamento, Meio Ambiente e Recursos Hídricos) - Universidade Federal de Minas Gerais, Belo Horizonte, 2007.

PICCHI, F. A.. Sistemas de Qualidade: uso em empresas de construção. Tese (Doutorado em Engenharia de Construção Civil e Urbana) - Universidade de São Paulo, São Paulo, 1993.

PINTO, T. P..Gestão Ambiental de Resíduos da Construção Civil: a experiência do SindusCon (SP). São Paulo: SindusCon, 2005

PINTO, T.. Perdas de materiais em processos construtivos tradicionais. São Carlos: Universidade Federal de São Carlos,1989.

RIBEIRO, P. K. P.. Gerenciamento do ciclo de aquisição de materiais na produção de edifícios. Dissertação (Mestrado) - Universidade Federal de São Carlos, São Carlos. 2006.

ROSA, F. P.. Perdas na construção civil: diretrizes e ferramentas para controle. Dissertação (Mestrado) Universidade Federal do Rio Grande do Sul, Porto Alegre, 2001.

ROSA, F. P.; PEIXOTO, F. M.; SILVA, M. K.; FORMOSO, C.T.. Proposta de uma classificação de perdas para a construção civil. In: CONGRESSO LATINO-AMERICANO DE TECNOLOGIA E GESTÃO NA PRODUÇÃO DE EDIFÍCIOS. Anais. São Paulo: Universidade de São Paulo, 1998.

SANTOS, A.. Método de intervenção em obras de edificações enfocando o sistema de movimentação e armazenamento de materiais: um estudo de caso. Dissertação (Mestrado em Engenharia Civil) Universidade Federal do Rio Grande do Sul, Porto Alegre, 1995.

SKOYLES, E. R.. Waste of materials on building sites. Building, v.226, n.6820, p.95-96,1974.

SOIBELMAN. L.. As perdas de materiais na construção de edificações: sua incidência e seu controle. Dissertação (Mestrado) - Universidade Federal do Rio Grande do Sul, Porto Alegre, 1993. 
SOUZA, R.; ABIKO, A.. Metodologia para desenvolvimento e implantação de sistema de gestão da qualidade em empresas construtoras de pequeno e médio porte. São Paulo: EPUSP, 1997.

SOUZA, R.; MEKBEKIAN, G.; SILVA, M. A. C.; LEITÃO, A. C. M. T; SANTOS, M. M.. Sistema de gestão da qualidade para empresas construtoras. São Paulo: Pini, 1995.

SOUZA, U. E. L.; PALIARI, J. C.; ANDRADE, A. C.; AGOPYAN, V.. Os valores das perdas de materiais nos canteiros de obras do Brasil. In: CONGRESSO LATINO AMERICANO TECNOLOGIA E GESTÃO NA PRODUÇÃO DE EDIFÍCIOS. Anais. São Paulo: PCC-USP, 1998.

SOUZA, U. E. L.; PALIARI, J. C.; ANDRADE, A. C.; AGOPYAN, V.. Perdas de materiais nos canteiros de obras: A quebra do mito. Revista Qualidade na Construção. São Paulo: Sinduscon, 1999. 